\title{
A Rapid Effect of Heat Girdling on Stomatal Conductance in Pearl Millet (Pennisetum americanum [L.] Leeke)*)
}

\author{
I. E. Henson ${ }^{* * 1}$ ) and V. Mafalakshmi ${ }^{2}$ )
}

1) Plant Breeding Institute, Maris Lane, Trumpington, Cambridge CB2 2LQ, UK.

2) International Crops Research Institute for the Semi-Arid Tropics, ICRISAT Patancheru P.O., Andhra Pradesh 502 324, India

Received April 1, $1985 \cdot$ Accepted April 3, 1985

\section{Summary}

A heat girdle, applied to the base of flag leaves of pearl millet, caused a rapid decline in stomatal conductance $\left(g_{s}\right)$. Stomata began to close within minutes of girdling (with $g_{s}$ reaching a minimum after about $5 \mathrm{~min}$ ) but then partly reopened before closing again $20-30 \mathrm{~min}$ from the start of treatment. The initial closing response could be deferred and initially counteracted by enclosing the leaf in a polyethylene bag. Cell death in the girdled zone appeared to be necessary for the response as mechanical pressure alone was ineffective. Only stomata «downstream» of a girdled zone (relative to the direction of xylem flow) were affected by the treatment; there was no lateral or «backward» transmission of a closing stimulus. No inmediate differences between control and girdled leaves could be detected in bulk leaf water potential or in abscisic acid content. The rapid effects of girdling on $g_{\mathrm{s}}$ are thus ascribed to a transient, localised disturbance in epidermal water relations probably induced by a temporary interruption in xylem flow.

Key words: Pennisetum americanum, heat girdling, stomatal conductance.

\section{Introduction}

Heat girdling is an effective means of preventing phloem export from leaves while permitting import of water, mineral ions and other substances via the xylem.-A brief, localised application of heat leading to the death of cells in a narrow zone across a petiole or lamina results in the accumulation of photosynthetic assimilates above the girdle, and causes stomata to close and photosynthetic rates to decline (e.g. Neales and Incoll, 1968; Setter et al., 1980 a, b). In addition, girdling results in an increase in abscisic acid (ABA) (Loveys and Kriedemann, 1974; Setter et al., 1980 b; Henson, 1984), a powerful hormonal promoter of stomatal closure (Raschke, 1975).

Recently, very rapid, transient reductions in leaf conductance and photosynthetic

*) Submitted as ICRISAT Journal Article No. 488.

*-*) Present address and address for correspondence: CSIRO Division of Plant Industry, Private Bag, P.O. Wembley, Western Australia 6014, Australia. 


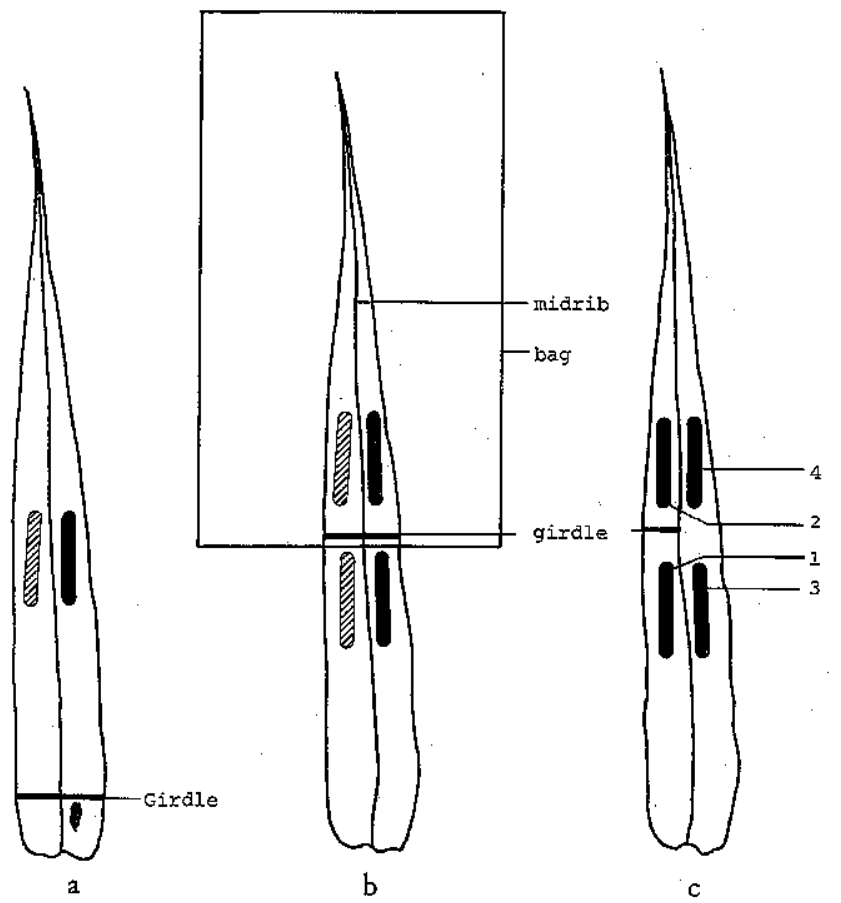

Fig. 1: Methods of treating and sampling leaves in the experiments: (a). leaf girdled near base, $g_{s}$ measured at mid-point; abaxial and adaxial surfaces sampled on opposite sides of the mid-rib. (b) leaf girdled at mid-point, $g_{\mathrm{s}}$ measured either side of girdle as indicated. Position of self-sealing clear polyethylene bag, when applied, is shown. (c) leaf girdled at mid-point on one side of midrib only; abaxial surface positions 1-4 sampled for $g_{s}$ as indicated. In all cases the area sampled, determined by the size of the porometer cup, was $100 \mathrm{~mm}^{2}(5 \times 20 \mathrm{~mm})$; $\amalg \Delta$ and $D$ indicate adaxial and abaxial areas respectively.

rate in response to girdling leaves of pearl millet, were observed under laboratory conditions (Henson, 1984). These responses appeared too rapid to be accounted for by accumulation either of photosynthetic assimilates or ABA. Since then we have carried out girdling experiments under field conditions, investigating both longerterm and short-term responses. Here, we report on a rapid effect of girdling on stomatal conductance of millet leaves and explore the basis for this response.

\section{Materials and Methods}

The experiments were carried out with pearl millet (Pennisetum americanum [L.] Leeke) plants established in field plots at ICRISAT Center, near Hyderabad, India, in the dry season (February to May) of 1984. Plants were grown from seed sown in early February in rows $0.75 \mathrm{~m}$ apart, being later thinned to c. $0.10 \mathrm{~m}$ apart within rows. The plants were regularly ir- 


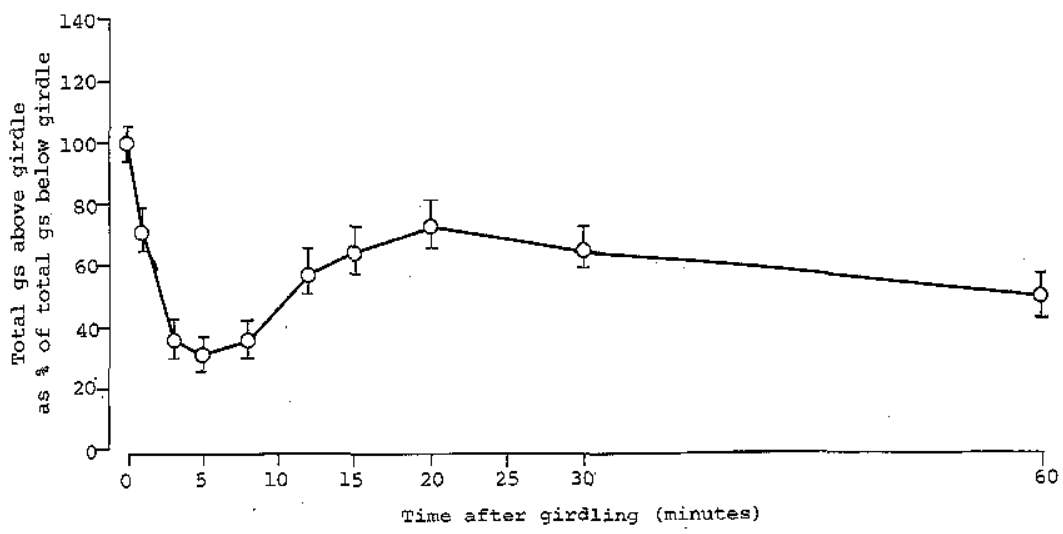

Fig. 2: Time course of response of stomata to girdling in cv. BJ 104. Leaves were girdled at the mid-point (Fig. 1 b), and $g_{s}$ of the apical portion was expressed as a percentage of $g_{s}$ of the basal portion which served as a control. Data are means of 6 leaves; vertical bars indicate $2 \times$ s.e. means.

rigated to minimise water stress. Measurements were made between 61 and 70 days after sowing on fully expanded flag leaves of main shoots during the grain-filling stage.

Leaves were heat girdled using a battery-operated resistive wire heating device. A sheathed heating wire, connected to four 1.2 volt nickel-cadmium batteries in series, was fixed along the mating faces of a pair of parallel-action pliers. The pliers were clamped across the leaf and both leaf surfaces were simultaneously heated for $10-20$ seconds. Positions of girdling used in different experiments are shown in Fig. 1. Stomatal conductance $\left(g_{s}\right)$ was measured with a Li-1600 steady-state porometer (Licor, Lincoln, Nebraska, USA), and leaf water potential $(\Psi)$ with a pressure chamber (PMS, Oregon, USA). Unless stated otherwise, all conductances are the total of the abaxial and adaxial surfaces. Measurements were confined to between $1000-1500 \mathrm{~h} \mathrm{In-}$ dian Standard Time when stomatal opening was normally maximal and irradiance was high ( $>1600 \mu \mathrm{mol} \mathrm{m}{ }^{-2} \mathrm{~s}^{-1}$ photosynthetic photon flux density). Air temperatures were, $c$. $35-39^{\circ} \mathrm{C}$.

The ABA content of leaves, which were rapidly frozen in liquid nitrogen on collection and subsequently freeze-dried, was determined using the method of Quarrie(1978).

\section{Results and Discussion}

Longer-term field experiments (Henśon and Mahalakshmi, 1985 and unpublished results) showed that girdling the base of the flag leaf resulted in a reduction in $g_{s}$ after one hour by $40-50$ per cent. A detailed time-course experiment, conducted to establish how soon $g_{s}$ was affected by girdling, showed the response to be rapid with $g_{s}$ initially falling to a minimum within c. 5 min after girdling (Fig. 2). There was then a partial recovery, followed by a further decline in $g_{s}$ after $20-30 \mathrm{~min}$.

To reduce variability associated with the use of separate control and girdled leaves, the effect of girdling in the above experiment was evaluated by comparing changes in $g_{s}$ of the apical portion of a leaf with those of its basal portion; with the leaf being 
Table 1: Effects of girdling half-way across the flag leaf at the mid-point, on abaxial $g_{s}$ (mmol $\mathrm{m}^{-2} \mathrm{~s}^{-1}$ ) of $c v$ BJ 104. Data are means of 3 leaves \pm s.e. mean. Positions sampled are illustrated in Fig. $1 \mathrm{c}$.

\begin{tabular}{lll}
\hline Position & $\begin{array}{l}c 2 \text { min } \\
\text { before girdling }\end{array}$ & $\begin{array}{l}c 6 \text { min } \\
\text { after girdling }\end{array}$ \\
\hline 1(below girdle) & $162 \pm 10$ & $174 \pm 26$ \\
2 (above girdle) & $112 \pm 16$ & $63 \pm 25$ \\
3 (opposite 1) & $173 \pm 5$ & $177 \pm 20$ \\
4 (opposite 2) & $110 \pm 7$ & $150 \pm 1$ \\
\hline
\end{tabular}

Table 2: Effect of enclosing the apical half of the leaf in a polyethylene bag on the response of stomata to girdling. Leaves were girdled at the mid-point and sampled as shown in Fig. 1 b. Leaves were enclosed within self-sealing bags $10 \mathrm{~min}$ before girdling and bags were removed just prior to measuring $g_{s} 5 \mathrm{~min}$ after girdling.

\begin{tabular}{|c|c|c|c|}
\hline \multirow[t]{2}{*}{ Treatment } & \multicolumn{3}{|c|}{$g_{\mathrm{s}}$ of apical portion as $\%$ of $g_{\mathrm{s}}$ of basal portion } \\
\hline & $\begin{array}{l}\text { Before bagging } \\
\text { or girdling }\end{array}$ & $\begin{array}{l}5 \mathrm{~min} \\
\text { after girdling }\end{array}$ & $\begin{array}{l}\text { ca. } 26 \mathrm{~min} \\
\text { after girdling }\end{array}$ \\
\hline $\begin{array}{l}\text { a) cv. B282, n }=5 \\
\text { Ungirdled } \\
\text { Girdled } \\
\text { Ungirdled, bagged } \\
\text { Girdled, bagged }\end{array}$ & $\begin{array}{l}\text { mean except } \\
83.2 \pm 3.8 \\
111.7 \pm 17.2 \\
123.1 \pm 11.2 \\
97.8 \pm 9.4\end{array}$ & $\begin{array}{c}(n=4) * \text { and } \\
103.0 \pm 12.9 \\
59.5 \pm 11.0 \\
252.0 \pm 51.3 \\
222.0 \pm 42.1\end{array}$ & $\begin{array}{l}=3)^{* *} \\
94.6 \pm 13.1^{* *} \\
80.4 \pm 5.3^{* *} \\
98.4 \pm 11.9^{*} \\
80.0 \pm 15.3\end{array}$ \\
\hline $\begin{array}{l}\text { b) cv. BJ 104, n = } \\
\text { Ungirdled, bagged } \\
\text { Girdled, bagged }\end{array}$ & $\begin{array}{l} \pm \text { s.e. mean } \\
77.8 \pm 8.0 \\
68.2 \pm 4.8\end{array}$ & $\begin{array}{l}201.4 \pm 16.1 \\
162.7 \pm 20.6\end{array}$ & $\begin{array}{l}90.6 \pm 8 \\
53.6 \pm 10.3\end{array}$ \\
\hline
\end{tabular}

girdled at the mid-point (see Fig. 1b). Other experiments (e.g. Table 1 and the experiment reported in Table 2) established that a girdle at the mid-point of a leaf only affected stomata which were above or «downstream» of the girdle. There was no «backwards» transmission of a closing stimulus, neither was there any lateral transmission as shown by examinig $g_{s}$ of the adjacent untreated side of a leaf girdled only half-way across to the mid-rib (Fig. 1 c; Table 1).

When the girdling device was clamped onto a leaf without current flowing, no effect on conductance was observed (results not presented). Hence, mechanical pressure by itself was ineffective in altering $g_{\text {s. }}$.

As the maximum reduction in $g_{s}$ occurred within 5 min after girdling (Fig. 2), untreated and basally girdled leaves (Fig. 1 a) of cv. BJ 104 were sampled at this time to tetermine whether girdling had affected bulk leaf $\Psi$ or ABA content. Immediately before girdling $g_{s}$ was $301 \pm 20 \mathrm{mmol} \mathrm{m}^{-2} \mathrm{~s}^{-1}(\mathrm{n}=6)$ and within 5 min after girdling it was reduced to $171 \pm 15 \mathrm{mmol} \mathrm{m}^{-2} \mathrm{~s}^{-1}$, a difference significant at $P<0.001$. Control zonductances at the time of girdling were $291 \pm 10 \mathrm{mmol} \mathrm{m}^{-2} \mathrm{~s}^{-1}$. There were, how- 
ever, no significant differences between control and girdled leaves in either $\Psi$ or ABA which averaged $-1.12 \mathrm{MPa}$ and $268 \mathrm{ng} \mathrm{g}^{-1}$ dry weight respectively.

Both the rapid and unidirectional nature of the response to heat girdling suggested that a transient interruption to water flow in the xylem might be affecting guard cell/ epidermal cell turgor relations, so affecting stomatal aperture. An inability to detect any differences in bulk leaf $\Psi$ both in this and an earlier study (Henson, 1984) could be due to the localised nature of the disturbance to tissue water relations together perhaps, with some re-equilibration of leaf water following leaf excision and before end-point determination in the pressure chamber.

In laboratory studies, decreasing the evaporative load on the leaf lessened the decline in leaf conductance and $\mathrm{CO}_{2}$ assimilation rate (Henson, 1984). Enclosing the apical part of leaves in the field in polyethylene bags, so raising the humidity around the leaf, substantially increased $g_{s}$ and initially prevented the fall in response to girdling (Table 2). After removal of the bag, $g_{s}$ of ungirdled leaves returned to normal, while that of girdled leaves declined further. Thus, the response to girdling was merely deferred by increasing the humidity. The results again point to a disturbance in leaf water relations following girdling. This was apparently transient as $g_{s}$ partially recovered (Fig. 2). Whether the stomatal response was purely hydropassive or involved a stress-induced internal redistribution of ABA (Cowan et al., 1982), or operated by some other mechanism, remains to be determined.

\section{Acknowledgements}

We thank Mr. P. V. D. M. Rao for valuable assistance with the experiments, Dr. S. A. Quarrie for the use of the heat-girdling device, and the UK Overseas Development Administration for financial support to IEH.

\section{References}

Cowan, I. R., J. A. Raven, W. Hartung, and G. D. Farquhar: Aust. J. Plant Physiol. 9, 489-498 (1982).

Henson, I. E.: J. exp. Bot. 35, 1419-1432 (1984).

Henson, I. E. and V. Mahalakshmi: Field Crops Res. 11, in press (1985).

Lovers, B. R. and P. E. Krifenmann: Aust. J. Plant Physiol. 1, 407-415 (1974).

NeALES, T. F. and L. D. INCOLL: Bot. Rev. 34, 107-125 (1968).

QuarrIE, S. A.: Analyt. Biochem. 87, 148-156 (1978).

RASCHKE, K.: Ann. Rev. Plant Physiol. 26, 309-340 (1975).

Setrek, T. L., W. A. Brun, and M. L. Brenner: Plant Physiol. 65, 884-887 (1980 a).

- - - Plant Physiol. 65, 1111-1115 (1980 b). 